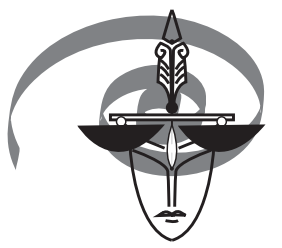

\title{
EUROPEAN
}

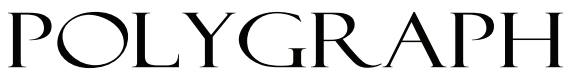

Volume $11 \cdot 2017 \cdot$ Number $4(42)$

DOI: 10.1515/ep-2017-0018

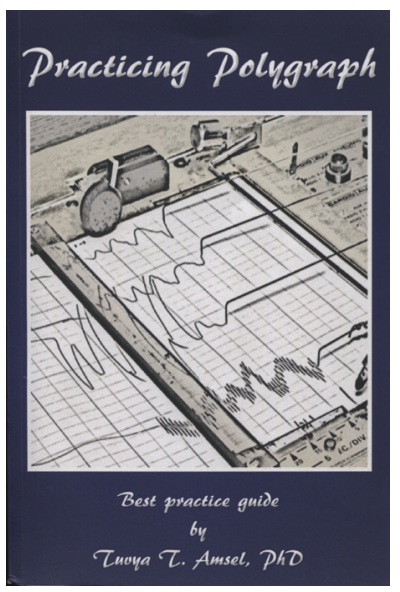

Tuvya Amsel, Practicing Polygraph, best practice guide, CreateSpace Independent Publishing Platform, North Charleston, 2017

A new book on polygraph examinations has been published by the CreateSpace Independent Publishing Platformin the United States; its author is Tuvya Amsel $\mathrm{PhD}$, an expert in polygraph examinations enjoying great respect in international polygraph circles. He has gained plenty of professional experience both in private and public sectors in Israel and the United States, as he has dealt with polygraph examinations for 45 years. As the subtitle suggests, the book is a guide for practitioners with precise instructions, descriptions of examination techniques, discussions of interfering with the recordings and anomalies in the curves, and information on conducting examinations on foreigners.

In its 320 pages, the book also contains a bibliography and a names index, while its eight chapters are 1. Basics of Practice, 2. Psychological Aspects in a Nutshell, 3. Test-Affecting Factors, 4. Pretest, 5. The Test, 6. Post-test, 7. Reexamination, and 


\section{Special Topics.}

In the introduction, the author quotes Talmud: "I have learned much from my teachers, more from my colleagues(from the University), and the most from my students". The motto is to bear out that the practice of polygraph examinations cannot be replaced with theoretical knowledge only. The author believes that, other than having thorough theoretical preparation, a good polygraphermust also prove life experience and practice. The author explains that the book wraps up his experience as well as that of other polygraphers who have shared it with him.

In Chapter 1 on the fundamentals of practice, which in fact is the introduction to the book, the author describes the moral and ethical problems a polygrapher may encounter. While discussing these he makes references to the American Polygraph Association Code, describes problems that a polygraphermay face, and quotes specific examples of such cases.

In the second chapter on psychological aspects in a nutshell, the author briefly describes why and since when people lie, and what such lies concern. What he writes would perhaps not differ from any other descriptions found in literature on the subjectif not for the fact that the author created a table of "symptoms of deception". It presents fairly clearly the usual reasons why people lie and verbal symptoms accompanying lying. Further in the chapter, Amsel also describes the fundamental theoretical assumptions of polygraph examinations, including the punishment theory and the conflict theory.

The successive chapter is devoted to the factors that make impact on the test. The author categorises the disruptions into external ones that may be present independently of the subject and the polygrapher, speaks of the "super damping" effect and the effect of first impression (the "Diablo effect") broadly discussed in the literature. He also discusses the ones that are wilfully caused by the examinee and include attempts at cheating (countermeasures). At the end of the chapter, the author notes a very important fact, namely the problem of fallibility or imperfection of human memory: under the impact of various factors, the human may develop an illusion of memories. This obviously may have a negative bearing on polygraph examination.

The fourth chapter devoted to the pre-test interview focuses on the problems at that stage. It lists the elementssuch an interview should contain, pays attention to what to focus on during the pre-test. The author also describes differences in running pre-test in case of focused control questions and ones that are to bring out guilty knowledge. In this chapter, the expert tries to answer the practitioner's questions concerning 
polygraph examinations, for example, whether it is possible to examine somebody who is ill and needs to take medications, how to answer the question about what polygraph is, etc.

This chapter also features a very interesting subchapter describing means to maximise the results of a polygraph examination. In other words, it is a collection of practical guidelines concerning the manner of conducting the pre-test interview.

The subject of the test "proper" contains interesting conclusions concerning the window of reaction. The author tries to address practitioners' problems concerning the duration of such a window, its proper start, and the time when the reaction should occur. Moreover, he points to the phenomenon of recurring reaction, that is, one that results from the subject's second thoughts that follow the window of reaction. Furthermore, the chapter discusses the question of anomalies that can be present in each and every polygraph channel.

The following chapterfocuses on the post-test and examines the elements that should be taken into consideration during the interview following the test. The author emphasises that it is important "not to burn the bridges" at the post-test stage. It is important to maintain a sense of comfort in the subject after the polygraph examination so that, should such a need occur, he or she were not afraid to undergo another procedure. The following chapter on retesting is closely connected to the issue, as it deals with the repeated examination of the same person, possible if the post-test interview had a positive conclusion. In this chapter, the author points out what to focus on at retesting.

The last chapter contains a collection of the author's experiences that cannot be strictly classified into one of the chapters described above. Here, the author discusses the question of how to defend a polygraph examination as a method, how to prove its high diagnostic value so that it does not remain controversial. In this he compares polygraph examinations to other forensic methods, including DNA tests and fingerprint identification.

The book is certainly very useful for the practitioner. It reads like a free interview with an older, experienced expert in polygraph examinationsat a polygraph seminar. In fact, it is a treasury of experience connected not as much with the methodology of practical examination but primarily with what happens during and around such a procedure. Beyond doubt, this matter is difficult to describe, as it is hardly measurable if at allperceptible. Nonetheless, it does not need any proof that the indirect factors described in the book impact not only the process of examinationbut also 
its very result. A proof of the above can be the fact that studies have shown that an expert who runs the examination can make more precise polygramanalyses than an expert working "blindly" on the results. Even though there are rigid norms for polygram assessment in polygraph sciences, the role of the expert, his or her approach to the examination and the subject all have a significant impact on the value and efficiency of the examination.

The book should be recommended, certainly and especially, to polygraph practitioners.

Michał Widacki*

\footnotetext{
*michal.widacki@gmail.com
} 